\title{
Nursing Intervention for Caregivers of Patients with Alzheimer's Disease regarding Burden of Care
}

\section{Zeinab Ibrahim Mahmoud Elsakhawy ${ }^{1}$, Howyida Sadek Abd El-Hameed ${ }^{2}$ and Doaa Mohamed Sobhy Elsayed ${ }^{3}$}

\author{
(1) Supervisor Nurse at Alshohada Central Hospital, Egypt, (2) Professor of Community Health \\ Nursing, Faculty of Nursing, Benha University, Egypt and (3) Assistant professor of Community \\ Health Nursing, Faculty of Nursing, Benha University.
}

\begin{abstract}
Background: Caregiver burden is a complex and multidimensional construct, which includes physical, psychological, social and financial consequences that can be experienced by family members caring for Alzheimer's patient. Therefore, it is essential to ensure that caregiver well-being is maintained. Aim of study: Was to evaluate the effect of nursing intervention for caregivers of patients with Alzheimer's Disease (AD) regarding burden of care. Design: A quasiexperimental design with pre and post-test was used. Setting: This study was conducted at the Outpatient Clinic of Benha Psychiatric Hospital, the Psychiatric Department of Benha University Hospital, and the Geriatric Outpatient Clinic of Al Khanka Hospital in Al-Qalubiya Governorate. Sample: A convenience sample consists of sixty caregivers and their Alzheimer's relatives in the selected settings. Tools of data collection: Four tools were used to conduct the study. I: A constructed interviewing questionnaire was developed by the researcher to assess sociodemographic data of $\mathrm{AD}$ patient and caregivers and assessment of caregiver's practice. II: Alzheimer's Disease Knowledge scale (ADK) to assess caregiver's knowledge. III: Zarit Burden Interviewing (ZBI) questionnaire to assess burden of caregivers and IV: Katz index of independence in Activities of Daily Living scale (ADL) to assess patient's independency. Results: There was improvement in caregiver's knowledge and practice after the intervention. Furthermore, there was a decrease in total burden score at post intervention. Conclusion: The educational intervention was successful in improving caregiver's knowledge and practice, as well as, reducing caregiver's burden. Recommendations: Caregivers should be routinely assessed and receiving educational intervention in out-patient clinics and social organizations should provide support to AD caregivers.
\end{abstract}

Key words: Alzheimer's Disease, Caregiver Knowledge and Practices, Caregiver Burden, Educational Intervention

\section{Introduction}

Aging is the time-dependent physiological functional decline that is also the most profound risk factor for many noninfectious diseases including AD. With the growing aging population and increasing burden of health care for people with AD. Research on this disease is rapidly expanding given the fact that $\mathrm{AD}$ is one of the best known aging-linked diseases (Xian et al., 2018).

Alzheimer's disease is a progressive neurodegenerative disorder with cognitive, functional, and behavioral alterations. AD is age related and is becoming markedly more common with the aging of the world's population. The estimation of $\mathrm{AD}$ in 2050 is 
that one in every 85 people will live with the disease. Nearly eightfold as many people have preclinical $\mathrm{AD}$ and are at risk for progressing to the manifestation disease (Cummings et al., 2018).

Alzheimer's disease is a type of brain disease, just as coronary artery disease is a type of heart disease. $\mathrm{AD}$ is also a degenerative disease, meaning that the disease becomes worse with time. $\mathrm{AD}$ is thought to begin 20 years or more before symptoms arise with changes in the brain that are unnoticeable to the affected person. Only after years of brain changes do individuals experience noticeable symptoms such as memory loss and language problems (Gordon et al., 2018).

Many people wonder what the difference is between Alzheimer's disease and dementia. Dementia is an overall term for a particular group of symptoms. The characteristic symptoms of dementia are difficulties with memory, language, problemsolving and other thinking skills that affect a person's ability to perform everyday activities. Dementia has many causes and AD is the most common cause of dementia (Sato et al., 2018).

Symptoms occur because nerve cells (neurons) in parts of the brain involved in thinking, learning and memory (cognitive function) have been damaged or destroyed. As the disease progresses, neurons in other parts of the brain are damaged or destroyed. Eventually, nerve cells in parts of the brain that enable a person to carry out basic bodily functions, such as walking and swallowing, are affected. Individuals become bed-bound and require around the clock care so that this disease is ultimately fatal (Alzheimer's Association, 2020).
Caregiving refers to attending to another person's health needs and well-being. Caregiving often includes assistance with one or more activities of daily living, including bathing and dressing, as well as multiple instrumental activities of daily living, such as paying bills, shopping and using transportation. Caregivers also provide emotional support to people with Alzheimer's as well as many other forms of help as, communicating and coordinating care with other family members and health care providers, ensuring safety at home and elsewhere, and managing health conditions (Friedman et al., 2015).

There is a growing consensus that professionals caring for people with Alzheimer's should acknowledge the role that family caregivers play in facilitating the treatment of the disease, and also professional should assess the well-being of family caregivers to improve overall disease management of the patient. The complex care challenges of people with Alzheimer's also require inter-professional collaboration and education (Werner, 2019).

\section{Significance of the study}

Worldwide, projective of Alzheimer prevalence is 25.73 million in year of 2005, while in 2010 the percent elevated to 30.12 million, and continued to increase annually until reached 35.26 million in 2015 and 41.27 million in 2020.This number are expected to increase to 56.55 million in 2030 to reach 106.23 in 2050. About 16.1 million Americans provide an estimated 18.4 billion hours of care valued at over 232 Billion dollars (Mary, 2018).

In Egypt, a recent study was done to assess the prevalence of $\mathrm{AD}$ in a wide range of Egyptian governorates and found that, one hundred twenty-six patients with $\mathrm{AD}$ were diagnosed out of 12,508 people aged 50 years; yielding a prevalence of one percent. 
Prevalence increases with age, from $0.34 \%$ for those aged $60 \leq 70$ years to $2.9 \%$ for subjects aged $70 \leq 80$ years, and $9.74 \%$ for those aged 80 years and more. $\mathrm{AD}$ is more common among females than males in all ages. Eighty-five percent of diagnosed patients are of mild and moderate degrees (EI Tallawy et al., 2019).

\section{Aim of the study}

This study aimed to evaluate the effect of nursing intervention for caregivers of patients with Alzheimer's disease regarding burden of care.

\section{Research hypothesis}

Caregivers of patients with Alzheimer's disease who will receive the nursing intervention will have higher knowledge \& practice and lower feeling of burden regarding care of Alzheimer's patients compared to pre intervention.

\section{Subjects and method: \\ Research design:}

A quasi-experimental design with pre and posttest was used to achieve the aim of the study.

\section{Setting:-}

This study was conducted at three health care settings included; the Outpatient Clinic of Benha psychiatric Hospital, the Psychiatric Department of Benha University Hospital, and the Geriatric Outpatient Clinic of $\mathrm{Al}$ Khanka Hospital in Al-Qalubiya Governorate.

Those settings were selected because they are the most concerned with Alzheimer's cases in Al-Qalubiya Governorate. This departments and outpatient clinics carry out short term treatment and monthly follow up of the cases.

\section{Sampling:}

Convenience sample that consists of sixty care giver and their Alzheimer's relatives out of seventy three of caregivers in the selected settings who fulfill the following criteria were included:

- Agree to participate in the study.

- Both genders

- To be a caregiver for elderly person with Alzheimer.

- Caregiver free from other medical problems

Tools for Data Collection: Four tools were used to collect the data:

Tool (I): A structured interviewing questionnaire: It was developed by the researcher based on literature review of the current and past available national and international references related literature about Alzheimer's caregiver by using a journal, textbooks and internet search, approved by supervisors and it was written in simple clear Arabic language: It comprised of five parts to assess:

The first part: It was designed to assess socio demographic characteristics of caregivers involved in the study.

The second part: It was designed to assess socio demographic characteristics of Alzheimer's patients involved in the study. The third part: It was designed to assess medical history of Alzheimer's patients and their caregivers.

The fourth part: It was designed to assess the changes appearing on Alzheimer's patient which consists of 16 statement covering changes of Alzheimer's patient.

The fifth part: Evaluated the reported practice of care givers with their patient behavior. It covered care giver response toward patient's behavior, sleep disturbance, memory loss, use of violence toward the patient or use of training methods to overcome patient problems.

\section{Scoring system:}

The scoring system of the reported practices was done as following: This section consists of 11 questions, each question consists of 3 right answers and the caregivers were asked to 
choose more than one answer. Each question was given 1 mark and the scoring was done according to the following:-

\section{Item}

Unsatisfactory

Satisfactory
Score

$<15$ mark

$>15$ mark
This tool was given to the caregiver before and after the intervention to assess the effect of the intervention on knowledge of caregiver.

Tool (II): Alzheimer's Disease Knowledge Scale (ADKS) is developed by Dieckmann et al., (1988). This scale contained 30 true/false items to assess knowledge about AD, based on current scientific understanding of the disease. It covers risk factors, assessment and diagnosis, symptoms, course, life impact, caregiving, treatment and management.

\section{Scoring system:}

The scoring system of caregiver knowledge was done as following: This section was to be checked as yes or no, each statement was given (1) score for correct answer and (0) score for wrong answer, and the scoring was done according to the following:-

$\begin{array}{cl}\text { Item } & \text { Score } \\ \text { Good } & >50 \% \\ \text { Poor } & <50 \%\end{array}$

This tool was given to the caregiver before and after the intervention to assess the effect of the intervention on knowledge of caregiver.

Tool (III): The Zarit Burden Interview (ZBI), developed by Nanluo \& Philip, (2010) which provides a comprehensive assessment of both objective and subjective burden, is one of the most commonly used burden measures and has been validated in many culturally or ethnically different populations. The (ZBI) is a 22-item instrument for measuring the caregiver's perceived burden of providing family care. The tool was used in this study to evaluate caregiver's burden of care. It included assessment of three main aspects: physical stress, social stress \& psychological stress.

\section{Scoring system:}

The (ZBI) is a 22-item instrument for measuring the caregiver's perceived burden of providing family care. The tool was modified by the researcher to include 28 items. The items of the sheet were scored according to 3 point Likert scale arranged as the following:-

$\begin{array}{lc}\text { Items } & \text { Score } \\ \text { Never } & 0 \\ \text { Sometimes } & 1 \\ \text { Always } & 2 \\ \text { Total or score } & \mathbf{5 6}\end{array}$

The result was categorized as the following:

$\begin{array}{llr}\text { From } & 1:<19 & \text { mild burden } \\ \text { From } & 18:<37 & \text { moderate burden } \\ \text { From } & 37:<56 & \text { sever burden }\end{array}$

This tool was given to the caregiver before and after the intervention to assess the effect of the intervention on burden level of caregiver.

Tool IV: Katz Index of Independence in Activities of Daily Living Scale (ADL): It developed by Wallace and Shelky, (2007). It is the most appropriate instrument to assess functional status as a measurement of the client's ability to perform activities of daily living independently such as performance in the six functions of bathing, dressing, toileting, transferring, continence, and feeding

\section{Scoring system:}

The response of questions was in the form of yes or no. Each answer with yes in the independence activity equal 1 score and each answer with no mean dependency and equal zero score and the Scoring system was categorized as the following:

Score from $0:<3$ indicate dependency.

Score from 3: 6 indicate independency.

\section{Content validity of the tools:}

Content validity of the tools was done by three of Faculty's Staff Nursing experts from the 
Community Health Nursing Specialties who reviewed the tools for clarity, relevance, comprehensiveness, and applicability and give their opinion.

\section{Reliability of the tools:}

Reliability of the tools were measured for testing the internal consistency by using testretest reliability for a group of 10 participants who were asked to fill the questions and were asked again to refill the same questions under similar condition on one or more occasion. The answers in the two testing were analyzed and computed for reliability. Overall alpha for ADL scale was 0.85 , which is accepted and indicates good internal consistency. The reliability for the ADKS was 0.60 and for $\mathrm{ZBI}$ the criticism subscale was 0.53 .

\section{Ethical considerations:}

The researcher followed all the ethical issues in conducting the research. The verbal consent agreements of subjects were taken after the purpose of the study was explained. Before data collection, subjects were given an opportunity to refuse the participation after explanation of the purpose of the study. Also they were reassured that the information would remain confidential and used for the research purpose only. The study maneuvers will not cause any harmful effects the participants.

\section{Pilot study:}

Before starting data collection, a pilot study was conducted using the developed questionnaire on 6 participants $(10 \%$ of the study sample). The pilot study was carried out to test the applicability and clarity of the constructed questionnaire and detect any obstacles or problems that might arise during the actual collection of data. Also, to estimate the time needed to fill the sheet with the total sample of the study the necessary modification and clarification was done. The pilot sample not included in the study to assure stability of the result.

\section{Field work:}

Data collection for this study was carried out at the first of October 2019 and completed by the end of March 2020. The data was collected by using self-administered questionnaire once permission was granted; the researcher was initiated collection of data through arranging meetings at the outpatient clinics of the selected settings. The questionnaire was filled while the patient and the caregiver were attending the outpatient clinic. Each patient who approved to participate in the study and fulfilled the selection criteria was asked to fill the questionnaire for a period of 20 minutes to collect socio-demographic data, and answering other tool questions. The obtained information (pre-test) served as baseline assessment for the caregiver. After collection of the pretest data, educational intervention was given to the caregivers based on their answers and weak points of their knowledge and practice. Post-test was done after the educational intervention to evaluate the effectiveness of the educational intervention on reducing level of burden of the caregiver and improving knowledge of the caregivers regarding Alzheimer's and the good practice to reduce burden. Patients who were included in the intervention were divided into groups, each group consisted of 10-15 patients. Each group attended 2 sessions and the duration of each session was 60 minutes.

\section{The educational intervention:}

Preparatory phase: Based on the baseline of assessment data obtained from the interview questionnaire and the literature review, an educational intervention for family caregivers was developed by the researcher and reviewed by a panel of experts in the field and then was written in Arabic language and printed out according to sample size.

\section{Implementation phase:}

The educational intervention was implemented for 6 Months in the mentioned 
settings. The total number of sessions was 6 sessions for each caregiver, 60 minutes for each session. At the beginning of the first session, an orientation to the educational intervention and its purpose was done. Each session was starting with quick summary on the previous sessions. All participants received the same content using simple teaching methods, discussion and hand out.

*Contents of the sessions:

- Included information about definition, causes, risk factors and types of Alzheimer's disease, stages of Alzheimer's disease and how to differentiate from other psychiatry disease.

- Sessions also included detailed explanation about the educational intervention, management of Alzheimer's patient, solutions of common problems that facing caregivers, types of stress that facing caregivers and coping mechanism with them.

\section{Evaluation phase:}

Evaluation was applied by comparing before and after the intervention score of knowledge and level of burden after one month from the intervention through reuse of the tools. To identify the differences, similarities and areas of improvement, using pre-and postanalysis of data was done.

\section{Statistical analysis:}

Data was coded and transformed into specially designed form to be suitable for computer entry process. Data was entered and analyzed by using SPSS (Statistical Package for Social Science) statistical package version 22. Graphics were done using Excel program. Quantitative data were presented by mean (X) and Standard Deviation (SD). It was analyzed using student $\mathrm{t}$ - test for comparison between two mean, however, if the data was not normally distributed, non-parametric tests were used. Qualitative data were presented in the form of frequency distribution tables, number and percentage. It was analyzed by chi-square $\left(\chi^{2}\right)$ test. However, if an expected value of any cell in the table was less than 5, Fisher Exact test was used.

\section{Result:}

Table (1): Illustrates the personal characteristics of caregivers. $50 \%$ of them were between 40 and 50 years with mean age $42.33 \pm 8.3$ year and female represented $75 \%$ of them. Also $46.7 \%$ were married and $45 \%$ had university education. $45 \%$ of the study sample have full time job, $70 \%$ were working; while $50 \%$ of them reported having income enough for basic need only. Regarding relation to patient and residency, $58.3 \%$ of caregivers were daughter in low and live in rural areas, while spouse \& siblings formed only $6.7 \%$ and $20 \%$ for each.

Table (2): Represents the socio-demographic characteristics of $\mathrm{AD}$ patient. $50 \%$ of the patients were above 80 years with average age $71.3 \pm 6.7$ years, and $75 \%$ of them were married. Regarding the residency, $63.3 \%$ of $\mathrm{AD}$ patients stayed at same caregiver home and $60 \%$ of them had income enough for basic need only, also $50 \%$ of them needed care more than 30 hours per week. Concerning education, only $3.3 \%$ of $\mathrm{AD}$ patients had university education, and just $8.3 \%$ were working as freelancer.

Figure (1): Shows that $59.7 \%$ of Alzheimer's patients were dependent on others in their daily living activities, while $40.3 \%$ of them were independent.

Table (3): Indicates a highly significant statistical improvement in total knowledge and practice score after the intervention $(\mathrm{P}=0.001)$.

Table (4): Shows statistically significant improvement in all parameters of burden among caregivers $(\mathrm{P}=0.001)$.

Figure (2): Illustrates the percentage distribution of burden categories at pre and post intervention. Regarding to sever burden, the percent decreased from $63.3 \%$ to $37.7 \%$ post the intervention. 
Table (5): Shows that the relation between burden level and dependence was statistically high significant at pre and post intervention (P.value $\leq 0.001^{* *}$ ) as mean score of burden level decreased with dependent $\mathrm{AD}$ patient from $51.36 \pm 11.9$ to $21.45 \pm 15.4$. While, the relation between burden and independence was only significant (P.value $<.05)$ as mean score of burden level decreased from 42 . $7 \pm 12.6$ to $36.2 \pm 11.9$ with independent $\mathrm{AD}$ patient at pre and post intervention.

Table (1): Frequency distribution of the studied caregivers according to their sociodemographic characteristics $(n=60)$.

\begin{tabular}{|c|c|c|c|}
\hline Items & Characteristics & No. & $\%$ \\
\hline \multirow{4}{*}{ Age of Caregiver } & $<40$ years & 14 & 23.3 \\
\hline & 40:50 years & 30 & 50.0 \\
\hline & $>50$ years & 16 & 26.7 \\
\hline & Mean \pm SD & \multicolumn{2}{|c|}{$42.33 \pm 8.3$} \\
\hline \multirow{2}{*}{ Gender } & Male & 15 & 25.0 \\
\hline & Female & 45 & 75.0 \\
\hline \multirow{4}{*}{ Social status } & Married & 28 & 46.7 \\
\hline & Single & 13 & 21.6 \\
\hline & Widow & 12 & 20.0 \\
\hline & Divorced & 7 & 11.7 \\
\hline \multirow{5}{*}{ Education level } & Illiterate & 12 & 20.0 \\
\hline & Read and write & 8 & 13.3 \\
\hline & Primary school & 8 & 13.3 \\
\hline & Secondary school & 5 & 8.4 \\
\hline & University education & 27 & 45.0 \\
\hline \multirow{4}{*}{ Employment } & Full time employee & 27 & 45.0 \\
\hline & Part time employee & 12 & 20.0 \\
\hline & Free Lancer & 3 & 5.0 \\
\hline & Not work & 18 & 30.0 \\
\hline \multirow{3}{*}{$\begin{array}{l}\text { In Income } \\
\text { sufficiency }\end{array}$} & Enough \& save & 10 & 41.7 \\
\hline & Enough for basics only & 47 & 50.0 \\
\hline & Not enough & 3 & 8.3 \\
\hline \multirow{5}{*}{ Relation to patient } & Spouse & 4 & 6.7 \\
\hline & Siblings & 12 & 20.0 \\
\hline & Daughter in law & 35 & 58.3 \\
\hline & Sister/brother & 6 & 10.0 \\
\hline & Nabors & 3 & 5.0 \\
\hline \multirow[t]{2}{*}{ Residency } & Urban & 25 & 41.7 \\
\hline & Rural & 35 & 58.3 \\
\hline
\end{tabular}


Table (2): Frequency distribution of Alzheimer's patient according to their sociodemographic characteristics $(n=60)$.

\begin{tabular}{|c|c|c|c|}
\hline Items & Characteristics & No. & $\%$ \\
\hline \multirow{4}{*}{ Age of patient } & $60:<70$ & 8 & 13.3 \\
\hline & $70: 80$ & 22 & 36.7 \\
\hline & $>80$ years old & 30 & 50.0 \\
\hline & Mean \pm SD & \multicolumn{2}{|c|}{$71.3 \pm 6.7$} \\
\hline \multirow{2}{*}{ Gender } & Male & 15 & 25.0 \\
\hline & Female & 45 & 75.0 \\
\hline \multirow{4}{*}{ Social status } & Married & 43 & 71.7 \\
\hline & Single & 4 & 6.7 \\
\hline & Widow & 10 & 16.7 \\
\hline & Divorced & 3 & 5.0 \\
\hline \multirow{2}{*}{ Same caregiver home } & Yes & 38 & 63.3 \\
\hline & No & 22 & 36.7 \\
\hline \multirow{3}{*}{ Income sufficiency } & Enough \& save & 6 & 10.0 \\
\hline & Enough for basic need only & 36 & 60.0 \\
\hline & Not enough & 18 & 30.0 \\
\hline \multirow{4}{*}{$\begin{array}{l}\text { Number of care hours } \\
\text { needed / week }\end{array}$} & 7 hours & 7 & 11.7 \\
\hline & 15 hour & 8 & 13.3 \\
\hline & 30 hour & 15 & 25.0 \\
\hline & $>30$ hour & 30 & 50.0 \\
\hline \multirow{5}{*}{ Education level } & Illiterate & 12 & 20.0 \\
\hline & Read and write & 23 & 38.3 \\
\hline & Primary school & 15 & 25.0 \\
\hline & Secondary school & 8 & 13.3 \\
\hline & University education & 2 & 3.3 \\
\hline \multirow{3}{*}{ Occupation } & Free Lancer & 5 & 8.3 \\
\hline & Do not work & 29 & 48.3 \\
\hline & With pension (retired) & 26 & 43.3 \\
\hline
\end{tabular}

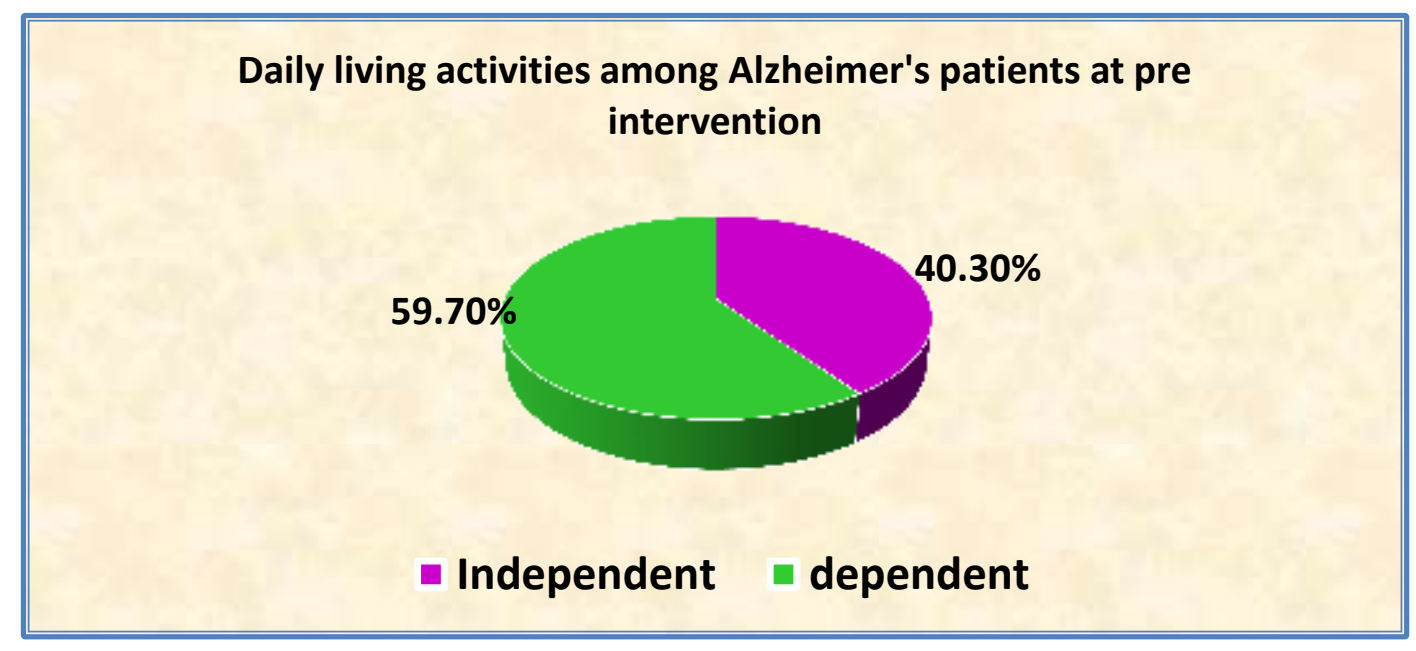

Fig (1): Percentage distribution of total daily living activities among Alzheimer's patients at pre intervention. 
Table (3): Comparison between total scores of knowledge and practices among caregivers at pre and post intervention $(n=60)$.

\begin{tabular}{|l||r|r|r|r|}
\hline \multicolumn{1}{|c||}{ Parameter } & Pre & Post & T.test & p.value \\
& & & & \\
\hline \hline Total Knowledge score & $10.4 \pm 1.17$ & $14.28 \pm 3.22$ & 8.91 & $0.001 * *$ \\
\hline Total Practice score & $19.35 \pm 7.7$ & $25.8 \pm 8.6$ & 8.49 & $0.001 * *$ \\
\hline
\end{tabular}

Table (4): Comparison between burden score in relation to types of burden at pre and post intervention $(\mathbf{n}=60)$.

\begin{tabular}{|l||l|l|l|l||}
\hline \multicolumn{1}{|c||}{ Parameter } & \multicolumn{1}{|c|}{ Pre } & \multicolumn{1}{|c|}{ Post } & \multicolumn{1}{c|}{ T.test } & \multicolumn{1}{c|}{ P.value } \\
& & & & \\
\hline \hline Physical & $5.53 \pm 2.54$ & $3.77 \pm 2.8$ & 3.499 & $0.001 * *$ \\
Social & $13.27 \pm 5.58$ & $7.35 \pm 3.44$ & 6.669 & $0.001 * *$ \\
Psychology & $22.07 \pm 8.79$ & $15.04 \pm 10.6$ & 3.852 & $0.001 * *$ \\
Total score & $40.87 \pm 16.8$ & $26.17 \pm 13.9$ & 5.017 & $0.001 * *$ \\
& & & & \\
\hline
\end{tabular}

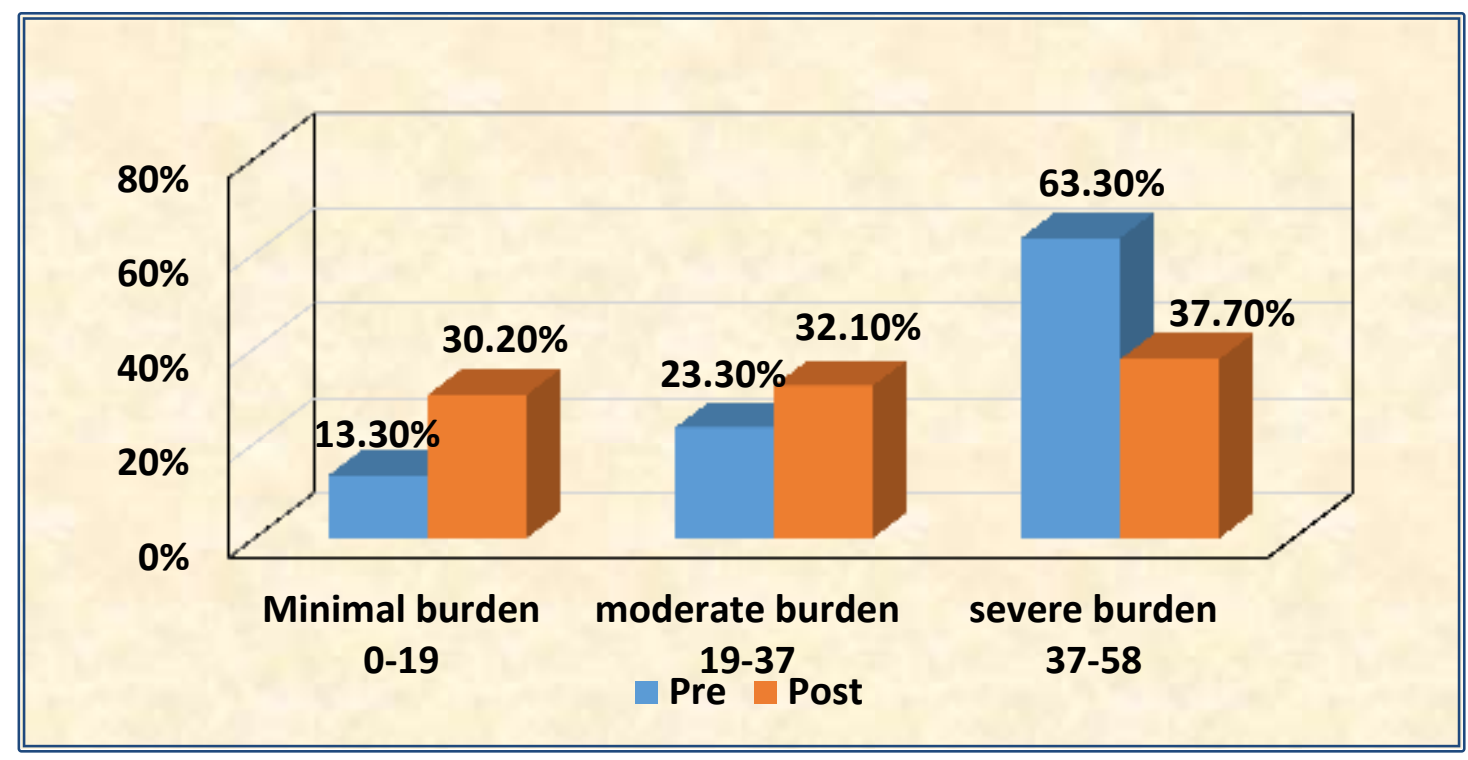

Figure (2): Percentage distribution of total burden categories among caregivers at pre \& post intervention. 
Table (5): Relation between burden level \& daily living activities of Alzheimer's patients at pre and post intervention $(n=60)$.

\begin{tabular}{|c|c|c|c|c|}
\hline \multirow{2}{*}{ Daily living activities } & \multicolumn{2}{|c|}{ Burden level } & \multirow{2}{*}{ T.test } & \multirow{2}{*}{ P.value } \\
\cline { 2 - 4 } & Pre & Post & & \\
\hline Dependent & $51.36 \pm 11.9$ & $21.45 \pm 15.4$ & 2.017 & $0.001 * *$ \\
\hline Independent & $42.70 \pm 12.6$ & $36.2 \pm 11.9$ & 9.017 & $\mathbf{0 . 0 3 1 *}$ \\
\hline
\end{tabular}

\section{Discussion:}

Alzheimer's disease, the most common cause of dementia, that presents an enormous health, social, economic, and personal challenges and affects the large and growing number of older people worldwide Prince et al. (2016) .Informal caregivers, typically family members, play a major role in caring for $\mathrm{AD}$ patients living at home, and the cost of informal care in $\mathrm{AD}$ represents the largest component of societal costs Wimo et al. (2016).

Caregiver burden can be defined as the caregiver's perception of the physical, emotional, economic, and social cost of the caregiving relationship. Identifying patient and caregiver characteristics associated with the caregiver burden is an important step towards determining interventions that may alleviate the burden of caring for patients with $\mathrm{AD}$ and may result in cost savings Reed et al., (2016).

Therefore, the present study was aimed to evaluate the effect of nursing intervention for caregivers of patients with Alzheimer's disease regarding burden of care.

Regarding to socio-demographic characteristics of studied caregivers, the present study illustrated that half of the study sample were between 40 and 50 years old (Mean $\pm \mathrm{SD}=42.33 \pm 8.3$ ), three fourths of them were females; about half were married and have university education. Nearly half of the study sample had full time job. Around three fourths were working; while half of them reported having enough income for basic needs only. Regarding relation to patient, more than half of caregivers were daughter in law, while the minority was spouse \& grandson. Half of caregivers provided more than 30 hours of care per week for their AD patient.

These findings are congruent with Alzheimer's Association, (2020) which declared that approximately two-thirds of caregivers are women, about $30 \%$ of caregivers aged 65 years or older, more than half of caregivers are married, over half of caregivers are providing assistance to a parent or in-law. A proximately $10 \%$ of caregivers provide help to a spouse with Alzheimer's disease or another dementia. Approximately half of dementia caregivers had a college degree or more education. The current study examined socio-demographic characteristics of AD patients and found that, the mean age of patients was $71.3 \pm 6.7$, and three fourths of them were female. This is on the same line with the report of Alzheimer's Association, (2020) which stated that, out of the total United States population, $10 \%$ of people who aged 65 and older has Alzheimer disease (AD). As the percentage of people with Alzheimer's disease increases with age, it is estimated by $3 \%$ in people age 65 to 74 years, and $17 \%$ among people age 75 to 84 years, plus, $32 \%$ between people age 85 and older. 
Regarding to gender, this association also reported that more women than men have Alzheimer's or other dementias, almost twothirds of Americans with Alzheimer's are women. Alzheimer's disease facts and figures, (2020) also found out the same findings and said that an estimated four percent of Alzheimer's patients are under 65 years old, while 45 percent are between $75 \&$ 84 years old and 45 percent are 85 years old.

Regarding daily living activities as a type of daily routine care, the present study revealed that, more than half of Alzheimer's patients were dependent on others in daily living activities, while less than half were independent, in details, around two thirds of the patients were dependent in their bathing, their dressing, and their feeding. Meanwhile, about half of them were independent in toileting, transferring, and continence. These results are in agreement with Alzheimer's Association, (2019) which announced that, nearly 80 percent of older adults with dementia in USA receive help with a daily personal care activity such as bathing, dressing, grooming or eating.

In contrast, only 20 percent of older adults without dementia need help with these activities. Also, One in three Alzheimer's caregivers provide help in bathing, feeding, or getting to and from the toilet a higher percentage than caregivers of other older adults, beside, about one-third of Alzheimer's and dementia caregivers deal with incontinence or diapers. These results is also supported by the Alzheimer's Association, (2017) which declared that, caregivers are providing certain activities for Alzheimer's patients at home such as getting the patient in and out of bed, feeding, dressing, getting to and from the toilet, bathing, managing incontinence and diapers.

The current study used an educational intervention to promote knowledge, practice and decreasing burden level of AD caregivers. After the intervention there is a significant difference in all dimensions of study hypothesis, regarding to knowledge level the mean score increased from $(10.4 \pm 1.17)$ to (14.28 \pm 3.22$)$, and practice level improved from $(19.35 \pm 7.7)$ to $(25.8 \pm 8.6)$. These results were in same line with Hepburn et al. (2018) who found that, interventions targeting caregivers, such as enhancing caregiver support, increasing 'time for self,' and providing caregivers with education and training in the management of behavioral and psychological symptoms of dementia have also been shown to be effective in decreasing burden and its impact on caregivers.

Similarly, Devor \& Renval, (2015) who used educational program with caregivers of patients with Alzheimer disease and studied its effect on caregiver burden, and found that, caregiver's experienced a statistically significant improvement in self-perceived competence, increasing their sense of control and ability to absorb new information, strengthening the belief that they can handle successfully many stressful events involved in caregiving, and minimizing anxiety associated with caregiving situations.

This study measured the three types of burden, (psychological, social and physical) among the studied caregiver and found that, there are enhancement in total burden score from $(40.87 \pm 16.8)$ before the intervention to $(26.17 \pm 13.9)$ after the intervention, also physical burden, social burden and psychological burden declined after the intervention. These results are in accordance with Kelsey et al. (2018) who did a study investigating a novel two-days intervention in decreasing symptoms of depression, anxiety, burden, and perceived stress in family caregivers of individuals with dementia.

The intervention focused on improving communication through teaching caregivers 
how to identify and validate the emotions of the individual with dementia. Findings showed a significant decrease in perceived stress that persists up to 6 months after the intervention, and on further examination, they found that this intervention supports participant's confidence in their ability to care for the individuals with dementia.

Regarding to severity of burden in this study, the percent decreased from nearly two thirds to about one third after the intervention. In contrary, Koca et al ., (2017) studied caregiver burden in different stages of Alzheimer's disease in Turkey and declared that, although dementia affects the caregiver negatively in many aspects, caregiving is a positive outcomes of dementia on the caregiver.

The present study revealed that there is a relation between burden and living at same house with $\mathrm{AD}$ patient, as most of caregivers who reported moderate level of burden were living with patient at same home, while, more than three fourths of caregivers who reported sever burden were living away from their AD patients. This finding is similar to Ferrara et al., (2018) who studied the prevalence of stress, anxiety, and depression in Alzheimer's caregivers in Italy and found that, caregivers are usually relatives who preferred to live in same home of their AD patients and they are usually daughters or wives. Those caregivers are reported physical health and psychosocial wellbeing.

Dissimilar, Mohamed et al., (2015)
who examined caregiver burden in Alzheimer's disease through cross sectional study and reported that, being a spouse was also found to be associated with intensified perception of burden, these findings proved that, behavioral problems were associated with change in caregivers burden. As a researcher I see that, being away or beside cared patient can cause burden, while, being with caregiver at same home can cause more burden due to dealing with all daily living activities of the patient.

Regarding the relation between burden level \& daily living activities of Alzheimer's patient .The current study shows that the relation between burden level and dependency level was highly significant at pre and post intervention. Similarly, Berger et al., (2016) who did a longitudinal study to examine the relationship between symptomatology of dementia and levels of burden and depression among family caregivers found a significant association between caregiver burden and activity of daily living scale over a two years observation period.

\section{Conclusion}

The nursing intervention succeeded to improve caregiver's knowledge from $10.4 \pm 1.17$ to $14.28 \pm 3.22$ and practices from $19.35 \pm 7.7$ to $25.8 \pm 8.6$ related to Alzheimer's disease and reduce burden level of Alzheimer's patient care. There was a significant relation between socio-demographic characteristics of caregivers with their knowledge, practice and total burden at pre and post intervention. Also there was a significant relation between burden level of caregivers with living place \& daily living activities of AD patients. Furthermore, a significant relation between burden level \& presence of chronic disease in caregivers were found.

\section{Recommendations:}

1- Educational intervention and awareness programs about nature of the disease and ways of management are needed for caregiver's in outpatient clinics in a wide scope for larger sample.

2- Caregivers should be routinely assessed in out-patient clinics in order to identify their burden level and needs which in turn, reduce the potential negative impact on Alzheimer's patient. 
3- Increase caregiver's awareness about governmental and non-governmental health centers that provide needed services through mass media and journals.

\section{References}

Alzheimer's Association, (2020). Alzheimer's disease facts and figures First published: 10 March 2020.Volume16, Issue3 . Pages 391-460 Available at : https://doi.org/10.1002/alz.12068.

Alzheimer's disease facts and figures, (2020). Journal of Alzheimer Assosiation. DOI: 10.1002/alz.12068 Alzheimer's Dement ;16:391-460. wileyonlinelibrary. com/journal.

Alzheimer's Association, (2019). Available at: http:// www. alzheimer. Cencus/Usa. DOI: 10.1002/ alz. 12068.

Alzheimer's Association. (2017). Alzheimer's. Disease Caregivers. FACT SHEET.Available at : http:// www. Alzimpact .org.

Berger et al., (2016). Longitudinal study on the relationship between symptomatology of dementia and levels of subjective burden and depression among family caregivers in memory clinic patients. J Geriatr Psychiatry Neurol 2016;18:119-128.

Cummingsa, J., Leea, G., Rittera, A., Zhongb, K. (2018). A Cleveland Clinic Lou Ruvo Center for Brain Health, Alzheimer Platform, Washington, DC, USA. Alzheimer's disease drug development pipe line. Alzheimer's \& Dementia: Translational Research \& Clinical Interventions.

Dieckmann, Zarit, and Gatz, (1988). The Alzheimer's disease knowledge test. 28(3):402-7: 10.1093/geront/28.3.402.

Devor \& Renval, (2015). An Educational Intervention to Support Caregivers of Elders with Dementia. American Journal of Alzheimer's . Disease \& Other Dementias.Volume Number 3. 233-241. Sage Publications. 10.1177/ 1533317508315336 . http:// ajadd. sagepub. com.

EL Tallawy, H., Farghaly, W.M., Abd El Hamed, M., Badry, R., Usama, K, H.,
Shehata, G.H., Tohamy, A. M., Abdulghani, KH., Ghanem, M., \& Sayed, M.A. (2019). Prevalence of Alzheimer dementia in Upper Egypt (desert areas). The Egyptian Journal of Neurology, Psychiatry and Neurosurgery . 55:29 https://doi.org/ 10.1186/s41983-019-0074-y.

Ferrara.M., Langiano, E., Brango, T., Vito, E., Cioccio, L., Bauco, C. (2018). Prevalence of stress, anxiety, and depression in Alzheimer caregiver. Health and Quality of Life Outcomes; 6:93. Data from http://www.ncbi.nlm. nih.gov/ pmc/ articles/ Friedman, E, M., Shih, R.A., Langa, K.M., Hurd, M.D. (2015). prevalence and predictors of informal caregiving for dementia. Health Aff ; 34(10):1637-41.

Gordon, B.A., Blazey, T.M., Su, Y., Hari, A., Dincer, A., Flores, S. (2018). Spatial patterns of neuroimaging biomarker change in individuals from families with autosomal dominant Alzheimer's disease; Doi: 78(4), 3444-3449.

Hepburn, Sherman, Lewis \& Bremer, (2018). The Savvy Caregiver Program: The Demonstrated Effectiveness of a Transportable Dementia Caregiver Psychoeducation Program. Journal of Gerontological Nursing. 33(3):30-6 DOI: $10.3928 / 00989134$ - 2001

Hirschman, Xie \& Feudtner, (2016). How does an Alzheimer's disease patient's role in medical decision making change over time? J Geriatr Psychiatry Neurol 2016;17:55-60.

Koca, E., Ozlem, T., BAKAR, S. (2017). Caregiver Burden in Different Stages of Alzheimer's Disease. Neuropsychiatry; 54: 82-6. DOI: 10.5152 /npa. 2017 .

Kelsey, N., Wilsona, S., Edmarie, G., Wiggsa, A. K., Savranskya, A., Tranela, D. (2018). A novel two-day intervention reduces stress in caregivers of persons with dementia. Alzheimer's \& Dementia: Translational 
Research \& Clinical Interventions; 450-460. Elsevier Journal.

Mary. D.F., Tarlow, B.J., Jones, R.N. (2018). Effects of an automated telephone support system on caregiver burden and anxiety: Findings from the REACH for TLC intervention study. Gerontologist; 43:544-560. Mohamed, S., Rosenheck, R., Lyketsos, K., Lon, S., Schneider, M. (2015). Caregiver Burden in Alzheimer's Disease: Cross Sectional and Longitudinal Patient Correlates J Geriatr Psychiatry; 18(15): 807-877. doi:10.1097/JGP .0b013e3181d 5745d.

Nanluo, S., \& Philip, R. (2010). Validity and reliability of the Zarit Burden Interview in assessing caregiving burden. PMID: 21063635. Oct; 39(10):758-63.

Prince, M., Bryce, R., Albanese, E., Wimo, A., Ribeiro, W., Ferri, C, P. (2016). The global prevalence of dementia: a systematic review and metaanalysis. Alzheimers Dement; DOI 9: 63-75.

Razani, J., Bernadette., M.A., Carla, O.B., Jennifer, T., Wong, M.A., Rachel, C., Cathy, A., \& Karen, J. (2017). Predicting Caregiver Burden from Daily Functional Abilities of Patients with Mild Dementia. J Am Geriatr Soc; 55(9): 1415-1420.

Reed, C., Belger, M., Agnello, c., Wimo, A., Argimon, J., Bruno, D., W. (2016). Caregiver Burden in Alzheimer's Disease: Differential Associations in Adult-Child and Spousal Caregivers in the GERAS Observational Study. Dement Geriatr Cogn Disord Extra DOI; 4:51-64. DOI: 10.1159/000358234.

Sato, C., Barthélemy, N.R., Mawuenyega, K.G., Patterson, B.W., Gordon, B.A. (2018). Tau kinetics in neurons and the human central nervous system. Neuron; Doi; 98(4):861-4.

Wallace, M., \& Shelkey, M. (2007). Katz Index of Independence in Activities of Daily
Living (ADL): Journal of the American Geriatrics Society, 37; 267-271.

Wimo, A., Reed, C.C., Dodel, R., Belger, M., Jones, R.W., Haro, J.M. (2016).The GERAS study: a prospective observational study of costs and resource use in community dwellers with Alzheimer's disease in three European countries-study design and baseline findings. J Alzheimers Dis; DOI.36: 385-399. Werner. P, (2019). Reflections on quality of care for persons with dementia: moving toward an integrated, comprehensive approach. Int Psychogeriatr. Mar; 31(3):3078.

Xian, X., Jiang, Q., McDermott, J., Dong, J. (2018). Aging and Alzheimer's disease: Comparison and associations from molecular to system level. WILEY AGING cell Journal. DOI: 10.1111/ acel.12802.

Zanetti, O., Geroldi, C., Frisoni, G.B. (2017). Contrasting results between caregiver's report and direct assessment of activities of daily living in patients affected by mild and very mild dementia: J Am Geriatr Soc : Doi; 47: 1 
التذخل التمريضي لمقدمي الرعاية لمرضي الألزهايمر فيما يتعلق بأعباء الرعاية المقدمه

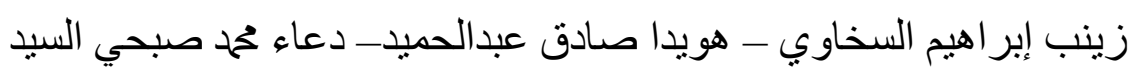

تعتبر الرعاية المقدمة لمرضي الألز هايمر عن طريق زويهم عملية معقدة ولها اتجاهات كثيرة قد تؤدي

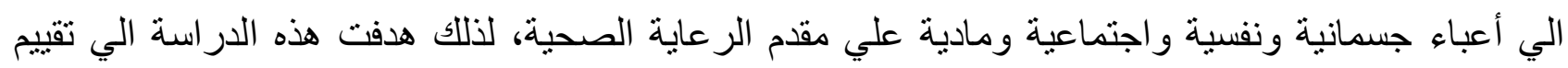
تأثنير التدخل التمريضي لتقليل العبء الواقع علي مقدمي الرعاية الصحية لمرضي الالزهايمر في مدينة بنها. وقد أجريت الدراسة في العيادات الخارجية لمستثفي بنها الجامعي ومستشفي النفسية ومستثفي الخانكه بمدينة بنها علي •T مريضا بالألزهايمرومقدمي الرعاية لهم. حيث كثفت النتائج عن وجود خلل في معلومات وممارسات مقدمو الرعاية تجاه مرضي الألزهايمر مما كان سببا في زيادة العبء عليهم، وأوضحت أليه أيضا

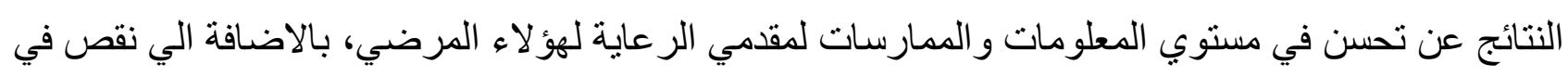

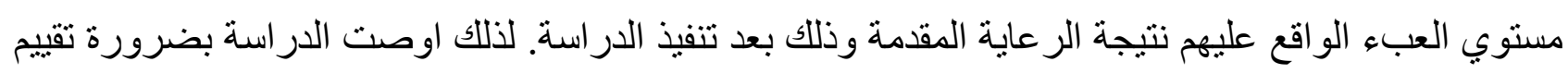

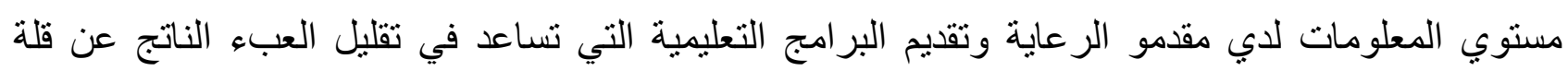
المعلومات و الممارسات الصحيحة لديهم. 